\title{
Inhalt
}

Einleitung -1

1 Die klitischen Personalpronomina - 11

1.1 Pronomina, wie die traditionelle Grammatik sie sah -12

1.2 Pronomina in der modernen Linguistik —15

1.3 Die zwei Typen von Personalpronomina im Spanischen - 25

1.4 Die freien Pronomina -28

1.5 Die Personalklitika - 32

$1.6 \quad$ Lektüre- und Analysetipps - 37

1.7 Aufgaben -37

2 Die differenzielle Objektmarkierung (DOM): die zwei Arten der Transitivität im Spanischen - 39

$2.1 \quad$ Terminologische Grundlagen - $\mathbf{4 1}$

2.2 Direkte Objekte, Transitivität und Rektion im Spanischen — 43

$2.3 \quad$ Indirekte Objekte -45

$2.4 \quad$ Präpositionalobjekte -47

2.5 Subjekte und Objekte im Lateinischen und in der Romania - $\mathbf{4 8}$

2.6 Differenzielle Objektmarkierung: Die zwei Typen spanischer Transitivität $-\mathbf{5 3}$

2.7 DOM im Spanischen: Grammatikalisierung und Semantik — 57

2.8 DOM und die „zwei Typen romanischer Syntax“— 60

$2.9 \quad$ Lektüre- und Analysetipps - 61

2.10 Aufgaben -62

3 Leísmo, Laísmo, Loísmo und die letzten Momente im Leben des spanischen Kasussystems -63

Das „etymologische“ Gesamtsystem der Personalpronomina — 65

3.3

3.4

Die abweichenden Systeme - 66

Leísmo: Versuch einer Erklärung - 72

$3.5 \quad$ Aufgaben -84

4 Die pronominale Doppelung (Reprise) und die Syntax der Klitika - 85

4.1 Syntax und Informationsvergabe - $\mathbf{8 5}$

4.2 Diachronie: Woher kommen (und wohin gehen) die Klitika? - 90

4.3 Resumptive Pronomina und Clitic Doubling - 96

4.4 Objektkonjugation im Spanischen - 101

4.5 Nachgedanken: „Was wird hier eigentlich gedoppelt“? 103 
4.6 Lektüre- und Analysetipps - 104

4.7 Aufgaben -105

5

5.1

5.2

5.5

5.6

5.7

6

6.2

6.3

6.4

6.5

6.6

6.7

6.8

7

7.2

7.3

7.4

7.5

7.6

8

8.1

8.2

8.3

8.4

8.5

8.6

8.7

Die Konstruktion AdjN und die Semantik der Adjektivvoranstellung -107 Einleitung - 107

$$
\begin{aligned}
& \text { Die Sequenzierung von N und Adj im attributiven Gebrauch - } 114 \\
& \text { Das Adjektivstellungsproblem im Spanischen: die }
\end{aligned}
$$$$
\text { Forschungslage - } \mathbf{1 1 6}
$$

Zwei Typen von Adjektivstellungstheorien — 118

Die Semantik der Konstruktion Adj-N $\mathbf{- 1 2 0}$

Lektüre- und Analysetipps - 126

Aufgaben - 127

Das Imperfekt zwischen Tempus, Aspekt, Textpragmatik und

\section{Modus - 129}

Die „linguistische Zwei-Welten-Lehre“_-129

Tempus: morphologische Konzeptualisierung der Zeit in der versprachlichten Welt - $\mathbf{1 3 2}$

Präteritum und Imperfekt im Spanischen — 134

Tempus und Aspekt - 135

Harald Weinrichs Kritik an der Aspekt-Theorie -141

Nicht-temporaler Gebrauch des Imperfekts —-147

Lektüre- und Analysetipps - 148

Aufgaben - 149

Tempus (und Aspekt?): Präteritum vs. Perfekt —151

Das HABEN-Perfekt als Verbalperiphrase - 152

Vom Lateinischen zum modernen Spanisch — 154

Hispanoamerika vs. Europa: Stufe 2 vs. Stufe 3-163

Harald Weinrichs Theorie: die Sprechperspektive —167

Lektüre- und Analysetipps - 168

Aufgaben -169

Der Subjunktiv - Modus oder syntaktischer Subordinationsmarker? — 171

Modus und Modalität _ 173

Kategorien des Modus im Spanischen -176

Theorien zum romanischen Subjunktiv —177

Der Subjunktiv erscheint ausschließlich im Nebensatz - $\mathbf{1 8 1}$

Der nicht-automatische Subjunktiv: Überreste von Modalität — 182

Lektüre- und Analysetipps - 186

Aufgaben - 187 
9 Tempus (und Modus?) - synthetisches vs. analytisches Futur - 189

9.1 Einleitung - 189

9.2 Tempus und Modus: allgemeine Reflektionen zum Futur — 191

9.3 Das Futur im Lateinischen -192

9.4 Fortentwicklung im (Alt-)Spanischen - 195

9.5 Die Grammatikalisierung des GEHEN-Futurs im Spanischen — 196

9.6 Das Futur im Esbozo - 202

9.7 Verbreitung und Vitalität der beiden Future - 203

9.8 Die beiden Future im Vergleich: die temporalen Funktionen - 204

9.9 Die modalen Funktionen des futuro simple - 207

9.10 Praktische Analysetipps - 210

9.11 Aufgaben - 211

10 Prädikation, Kopula und das ser/estar-Problem - 213

10.1 Prädikative Konstruktionen - 214

10.2 Prädikation im Spanischen - 218

10.3 Entwicklung vom Lateinischen zum Kastilischen - 219

$10.4 \quad$ Unproblematisch: die nicht-prädikative Verwendung mit ser und estar-220

10.5 Das ser/estar-Problem: prädikative Konstruktionen — 223

$10.6 \quad$ Einige klassische Lösungsvorschläge — 224

10.7 Kognitionslinguistische Analyse der Konstruktionen SER + ADJP und ESTAR + ADJP -227

10.8 Von keiner Regel erfassbar: lexikalisierte Konstruktionen - 229

10.9 Praktische Analysetipps - 229

10.10 Aufgaben - 231

Bibliographie -233 
